\title{
THE UNIVERSITY OF JOHANNESBURG MERGER: ACADEMICS EXPERIENCE OF THE PRE-MERGER PHASE
}

\author{
Goldman GA \& Van Tonder C, University of Johannesburg
}

\begin{abstract}
Purpose of the study: The aim of this study is to gain an understanding of the merger experiences academic staff were exposed to during the pre-merger phase of the University of Johannesburg merger. Of particular interest is how these experiences translate into acceptance of the merger amongst academic staff. The study was borne out of the transformation of the higher education landscape in South Africa, which is typified by a spate of mergers between higher education institutions.
\end{abstract}

Design I methodology I approach: As the purpose of the study was, inter alia, aimed at understanding the merger experiences of academic staff, the study was conducted according to an interpretive research paradigm, where interpretation of data calls for an insider perspective, in order to "see things through their eyes" as it were. In this regard, a qualitative methodology was employed.

Findings: Findings indicate that academic staff members at the University of Johannesburg experience two distinct mental states during the pre-merger phase. Following the announcement of the merger, reaction and experience tend to be emotionally driven but as merging efforts become more concrete over time, this emotive state is replaced by a more rationally driven disposition.

Implications: The distinction between an emotive and rational demeanour during the pre-merger phase of a merger affords managers and leaders the opportunity to plan change interventions in such a way that irrational, emotive responses and behaviour do not hamper progress in terms of merger implementation. In a more general sense, this study highlights the process of transition individual staff members pass through as they have to come to terms with the changes brought about by a merger

Originality I Value: The majority of merger literature, as well as change literature, focuses on the organisational context of change during a merger. Limited literature exists on the personal effects of a change event such as a merger. This study can thus contribute to the understanding of the personal effects of change during a merger. Furthermore, scant literature exists concerning mergers that are not driven by "conventional" economic motives. As the University of Johannesburg is this type of merger, this study presents the opportunity of gaining a better understanding of this type of merger.

Key words and phrases: ideological mergers; pre-merger; personal outlooks; institutional predisposition; personal fears and concerns

\section{INTRODUCTION}

Contrary to the generally optimistic view of mergers that underlie this form of institutional change, there is substantial evidence to suggest that mergers and merger-related activities are not as successful as they were intended to be (Cairncross, 2003:168; Eriksson, 2004:3; Eriksson \& Sundgren, 2004:11; Fulop, Protopsaltis, King, Allen, Hutchings \& Normand, 2005:129; Lew-Kiedrowski, 2001:22; Lundback \& Horte, 2005:220; Papadakis, 2005:236; Peterhoff, 2004:10-11; Schafer, 2004:48 and Van Tonder, 2004a:53). Reported success rates for mergers are surprisingly low and the incidence of failure reportedly varies between 40\% and 80\% (Appelbaum, Gandell, Shapiro, Beslile, \& Hoeven, 2000b; Panchal \& Cartwright, 2001 and Papadakis, 2005). The majority of mergers essentially fail to satisfy the original intention behind their initiation.

Regardless of the deemed success (or otherwise) of mergers, the consequences and implications of mergers are substantial. Mergers inevitably lead to a reassessment of merged operations and activities and often result in re-organisation, rationalisation and redundancies (CIPD, 2000:2) which, in turn, prompts a reconfiguration of functional teams that contribute to confusion around reporting lines - to the extent that people lose their "mental maps" of how the workplace functions (Fulop et al., 2005:127 and 
Lundback \& Horte, 2005:232). Any attempt at integrating corporate entities whether a merger, an acquisition or a joint venture, has very real Human Resources (HR) implications (CIPD, 2000:3; Nel, Marx \& Burchell, 2004:4 and Papadakis, 2005:239).

Failing to adequately attend to HR issues during mergers in most cases leads to "merger syndrome" - a series of consequences typically associated with mergers which include stress, fear, anxiety, depleted productivity levels, increased absenteeism, declining job satisfaction, resistance to change and a feeling of defeatism (Anon, 2001a:3; Bews, 2001:36; Du Plessis, 2004:9; Eriksson \& Sundgren, 2004;11; Fulop et al., 2005:128; Garrat, 2000:19; Kotter, 2002:27-28; Lessing \& Maritz, 2001:10; Lew-Kiedrowski, 2001:23; Papadakis, 2005:241; Van Tonder, 2004a:61 and Wenburg, 2001:7).

There is evidence to suggest that all hope is not lost when mergers become topical. For one, there seems to be a trend to actively seek areas where value will be added in a merger (CIPD, 2000; Eriksson \& Sundgren, 2004:11-12 and Schafer, 2004:48); to guard against demoralising staff and destroying knowledge capital (Anon, 2001a:3; Cairncross, 2003:76 and Collins \& Porras, 2000:50-53) and to actually create employment in a merger (Ensor, 2003:1 and Eriksson \& Sundgren, 2004:11). Despite this, there is still a general sentiment that HR related issues are not receiving enough attention in a merger (Anon 2001a:2; CIPD, 2000:9; Lessing \& Maritz, 2001:10; Lew-Kiedrowski, 2001:22 and Papadakis, 2005:240).

The HR-related issues that emanate from corporate mergers are many and varied (Fulop et al., 2005:119120 and Peterhoff, 2004:6-8). Included in these are issues that:

- are more mechanistic in nature such as organisational architecture, HR information systems and payroll;

- $\quad$ need to be negotiated, such as conditions of service, disciplinary code and retrenchment policies and

- "soft" issues such as staff development, wellness and change management.

It can be postulated that the first two types of issues listed above are crucial for a merger not to fail. These are visible aspects that would appear on any kind of checklist of issues to attend to during a merger. It is the soft issues however that will determine whether the merger succeeds or fails. Arguments such as these highlight the centrality of the 'human factor' in mergers and their consequences, regardless of whether they are considered successful or otherwise. At the same time, these views provide a reasonable platform from which to anticipate the challenges and likely outcomes of mergers that broadly conform to the descriptive parameters of those mergers on which the literature reports. Whether these parameters still hold when a merger, in character, clearly departs from these descriptive characteristics, is uncertain, as the literature does not clearly differentiate between different types of mergers.

Examples of such mergers that deviate in character from the conventions observed in respect of business-oriented mergers are the recent wave of mergers in the South African Higher Education sector, which was initiated by the Department of Education. These mergers follow in the wake of a major sociopolitical transformation of civil society and its institutions, and were informed by political and ideological motives and not economic growth, institutional survival or sustainability (cf. Mokadi, 2002). Apart from this, these mergers were imposed (enforced). Unlike business-orientated mergers where the merging partners generally harbour at least an expectation of improved functioning or returns and hence normally enter the merger with a degree of willingness, the merging parties in most of these enforced higher education mergers were substantially unwilling merger partners.

What complicates the higher education mergers is that, if these mergers go awry, they cannot be resolved through the subsequent selling off or outsourcing of business operations, effecting leveraged buyouts, further takeovers, injection of additional capital, or simply closure of operations. Moreover, if it is acknowledged that the dynamics of mergers and acquisitions are substantially similar, a sense of the implicit risk in mergers and acquisitions can be obtained from research, which reveals that up to $47 \%$ to $50 \%$ of senior executives of an acquired company leave within one year and almost $72 \%$ to $75 \%$ within three years (Fulmer \& Gilkey, 1988 and Hattingh, 2004). Indeed, the loss of top calibre staff is a common consequence of all forms of disruptive institutional change (cf. Van Tonder, 2004b; 2005). This is a situation that universities can ill-afford as they revolve around their academic staff, whose research 
outputs, expertise and reputations contribute to the overall reputation of the university that employs them. Academics' experience of a merger could have a profound effect on overall institutional performance and ultimately adversely impact on its stature, reputation and marketability.

Although primarily concerned with the experience of a merger in the higher education sector, the results of the study could shed further light on the role of context during major corporate change beyond this research setting - a substantial need in change research as the latter has been criticised for its lack of contextual, procedural and theoretical perspectives (Pettigrew, 1990 and Van Tonder, 2004a).

The ensuing discussion briefly contextualises the research setting, outlines the methodology that was employed and presents the primary results. The paper concludes with a consideration of the main implications for managerial practice.

\section{THE RESEARCH SETTING}

During the past three years, some eight mergers of universities and technicons took place in the South African higher education sector. This paper is concerned with a particular merger that was announced on 31 May 2002 and forms part of this restructuring of the higher education landscape (TWR, 2002a and TWR, 2002b). It entailed the merging of the Rand Afrikaans University (RAU), the Technikon Witwatersrand (TWR) as well as two campuses of Vista University - namely the East Rand and Soweto campuses. In the interest of clarity and brevity, this comprehensive merger process in all its complexity and dynamics is simply referred to as the 'UJ merger' in the remainder of this paper. The UJ merger would unfold in two discernable stages (Goldman \& Coetzee, 2004; Goldman, 2005 and TWR, 2003a) i.e. the incorporation of the two Vista campuses into RAU by 1 January 2004; and the merging of RAU and TWR - effective 1 January 2005.

The reasons advanced by the South African government for the mergers in higher education, and therefore the merger of RAU and TWR into the University of Johannesburg, suggest that these mergers were politically and ideologically motivated (cf. Mokadi, 2002). The UJ merger, which marked the establishment of the University of Johannesburg (UJ) (the largest residential university in South Africa) on 1 January 2005, moved from the planning phase to the implementation of the merger. Large scale, multidimensional and multi-facetted change followed from the merger, which resulted in the formulation of a new strategic plan (UJ, 2005a), which, in turn, formed part of a larger institutional change initiative (UJ, 2005b). A change governance structure was established (Laetoli, 2005 and UJ, 2005b) to ensure that change efforts were not dealt with in isolation but were directed at strategic level yet implemented and coordinated at functional level (Goldman, 2005 and UJ, 2005b).

Notwithstanding these measures, large-scale change of the nature indicated here always has undesirable side effects (Applebaum, Henson \& Knee, 1999), which most often manifests in unfavourable employee reactions (Armenakis \& Harris, 2002) and increased (voluntary) staff turnover that incurs significant direct and indirect costs for the institution (Morrell, Loan-Clark \& Wilson, 2004). As was argued previously, the academic stature and success of a university hinges on its academic staff. Their research outputs, expertise and reputations sustain the overall reputation of the university, which in turn attracts high caliber students. The manner in which academics experience the merger dynamics is consequently a critical consideration, as this can have a profound impact on overall institutional performance and therefore its stature, reputation and marketability. The last thing institutional management would want is that their top academics find employment at other institutions while the university finds itself in the midst of disruptive change - a common consequence of disruptive institutional change (cf. Van Tonder, 2004b; 2005).

The central research question that consequently informed this study and directed its focus, design and execution, addressed the issue of how academic staff experienced the ' $U \mathrm{~J}$ merger'? By focusing on academics' experience, the study aimed to gain a deeper and enriched understanding of how academics (as employees) experience the pre-merger phase of the ' $U \mathrm{~J}$ merger' and how their experiences translate into subsequent acceptance of and commitment to this merger following the large scale change to which they were exposed. 
The paucity of literature on the individual experience of large-scale change in general and mergers in particular, further accentuates the need for research that seeks to fathom individual dynamics during such events. The value of the study, however, is further indicated by the unique features of the UJ merger, which included the non-commercial, indeed, ideological and socio-political origins of the merger. The fact that academics are often considered a breed apart may also shed light on the experience of the merger by a specific group of people and comment on arguments that traditionally consider people hailing from specific occupational categories (e.g. engineers, accountants, medical practitioners) to be substantially different, and hence needs to be treated differently.

\section{RESEARCH METHOD}

The current study forms part of a more encompassing research project, which investigated the role of leadership in academics' willingness to accept change in a merger setting. The current study, however, focused more specifically on academic staff's experience of the University of Johannesburg (UJ) merger. The nature of the research question suggests an exploratory study, which, as Mouton (1996:103) argues, attempts to gather new data and "facts" and to establish whether there are interesting or novel patterns in the data. Due to the fact that qualitative methods are generally used for exploratory research - in particular when the research activities attempt to identify, describe and generate explanations for phenomena (Crabtree \& Miller, 1992:6) as is the case in this study, a qualitative design was chosen. Moreover, the choice of a qualitative design is generally considered appropriate when little previous research has been conducted in the subject domain (cf. Mouton, 1996:102-103). The qualitative design was effected through a case study approach, which allows investigation of phenomena as "bounded systems" (Henning, Van Rensburg \& Smit, 2004). Any social entity can be demarcated (is thus bounded) by parameters that enable exposure of its distinctive dynamics. Data is then solicited from within the parameters of the bounded system or case. In this study, the focus is on change in the University of Johannesburg, which can be viewed as a bounded system with clear parameters and a specific and unique dynamic.

The ontological platform for the study is indicated by the study's point of departure, namely the impact of a merger on people. The study focuses on (investigates) the experience of individual academics and thus works at the level of individual feelings, attitudes, beliefs, views, and understanding of and during the merger. The latter are of course personally and socially constructed and fit an interpretive research paradigm. In this regard, Neuman (2003) argues that researchers operating from within an interpretative paradigm strive to systematically analyse socially meaningful actions. They achieve this through direct observation, in order to understand how people create and maintain their social worlds. From an epistemological perspective, it follows that first hand accounts (e.g. verbatim narratives) of how the merger was experienced, and obtained directly from those who experienced it, will be most suited as a vehicle of knowledge.

The research population for the study comprised all full time academic personnel in the employ of the UJ, which includes the job categories of lecturers (junior lecturers, lecturers and senior lecturers), professors (associate professors and full professors), and academic managers (Heads of Department; Heads of School and Departmental Chairs). As with most qualitative studies, non-probability sampling was employed in this study. However, for reasons such as the distinctly different nature and cultures of the merging institutions, variation in campus locations, differences in structures, faculties, hierarchical levels and management philosophies, it was felt that the traditional approaches to sampling in qualitative studies be elaborated to allow for greater diversity in perceptions and experiences related to the merger. As a result, the sample size was increased and structured on a quota basis, which would ensure participants from all faculties, across all campuses. This resulted in the selection of two research subjects per faculty per campus, except in those instances where the faculty has a presence of less than 10 full time academic employees on any particular campus. In these instances, sampling numbers were reduced. In this manner, a sample of 40 research subjects was arrived at.

Consistent with a modernist value-framework, open-ended, semi-structured interview techniques were used for data gathering (cf. Denzin \& Lincoln, 2005), which, in this study, translated into an interview schedule consisting of three open-ended questions. These questions prompted respondents to share 
their experiences, feelings, perceptions and expectations of the merger. When issues that emerged from the interviewee responses were vague or lacked clarity, follow-up questions were used to illuminate the issue. Grounded theory was employed as an overarching method for 'structuring' the gathered data and deriving meaning from it. As all interviews were recorded verbatim, this had to be transcribed, after which the data was coded to facilitate categorisation and extraction of prominent themes, and ultimately theory building. Consistent with Corbin and Straus' (1990) grounded theory approach, an open, axial and selective coding convention was utilised to extract themes from the data. Three distinct rounds of data coding were thus performed. During the first round of coding ('open coding'), all sentences (the designated unit of analysis) were allocated labels with the aid of an evolving codebook methodology. As a consequence, every similar meaning phrase (sentence) received the same label while every 'new' meaning phrase was allocated a new label. From inspection of both the range and frequency of labels, a series of (labeled) categories emerged (cf. Babbie \& Mouton, 2004; Henning et al., 2004 and Neuman, 2003). Open coding, as generally applied in grounded theory studies, resembles factor analysis in quantitative analyses, in that it seeks to reveal communality in the dataset. Patterns in the quantitative dataset are typically labeled 'factors' or 'components' whereas, in qualitative datasets, these patters present as recurring themes. It is effectively a data-reduction technique that enables more salient data categories to surface. During axial coding (the second round of coding), relations and linkages among categories (themes) that were extracted during open coding are revealed, while selective coding (the third round of coding) enables a construction of the essential 'narrative' (and 'theory') of the entire dataset as it pertains to the experience of the merger.

The scope of this paper, as directed by the research question, focuses on the primary themes (or categories) that emerged from open coding. These themes are presented in the ensuing 'results' section, while the implications for management are briefly considered in the 'discussion' section.

\section{RESULTS}

Resultant from the analytical process, emergent themes where identified which afforded insights into academics' initial reaction to the merger and their pre-merger experiences. These themes revealed that individuals interpreted the merger from a specific paradigm (theme 1), which could be viewed as a contributing factor in terms of their initial reaction to the merger (theme 2). The pre-merger phase was also typified by (mainly emotively driven) fears and concerns about the impact the merger will have (theme 3). However, a shift in attitude was apparent over time as the gravity of the merger filtered through (theme 4) and efforts were more formally directed

\section{Theme 1: Individuals Interpret the Merger According to a Specific Paradigm}

Reflections concerning the institutions' staff afforded one the opportunity of understanding how subjects viewed the institutions they hailed from. This paradigm, or "institutional predisposition" had a definite impact on how individuals reacted to the merger. Ex-RAU staff harboured generally very positive sentiment toward this institution, resulting in a positive institutional pre-disposition. Evidence suggests that levels of job satisfaction were generally quite high amongst academics at this institution. Although perceived as an institution with a good reputation amongst technikons, ex-TWR staff harboured generally negative, and at times scathing, sentiment toward the TWR, resulting in a negative institutional predisposition. Vista University seemed to be a university typified by autonomy and motivated staff. Unfortunately, mismanagement led to the eventual dissolution of Vista at the end of 2003. Although uncertainty typified Vista, morale seemed to be generally high, resulting in a positive institutional predisposition. It seems as though the factors that lead to the dissolution of the university had no effect on the prevalent ethos and operational dynamic of the institution. The following statements exemplify the abovementioned views:

And you were left, circumstances were created, computers were supplied, office space was supplied for you to be able to do your work

- Professor: Faculty of Education, ex-RAU Well, my perception was that, over the years, management had become quite wishy-washy and there was a lot of inefficiency. I just felt the place was going nowhere, fast 
- "Angela": Faculty of Natural Sciences, ex-TWR

Like I said, Vista worked, and we were far more geographically dispersed; across the whole country. We worked because we wanted to work, you know. We were motivated

- Senior Lecturer: Faculty of Management, ex-Vista

\section{Theme 2: Individuals' Reaction to the Merger.}

The announcement to merge was met with varied reactions from staff, ranging from extreme negativity, through indifference, to extreme optimism. Though reactions were generally positive; it was striking, however, that reactions emanating from the various merging institutions tended to be polarised. Reactions from the ex-RAU fringed on indifference, but exhibited a large amount of negative reaction; a product of staff possessing a positive institutional predisposition toward RAU. Reactions from the exTWR, on the other hand, tended to be largely positive due to the negative institutional predisposition evident at TWR. Ex-Vista staff, although eventually incorporated into RAU, tended to air negative opinions, but cited different reasons for this negativity from the ex-RAU staff.

When specifically looking at the negative reactions expressed, disagreement with the reasons provided by government to merge was most prominent, although some of the reasons provided (such as better access to HEl's; rationalisation and consolidation of the HEI landscape) found favour with a number of interview subjects. The overwhelming sentiment, however, was that the merger was politically motivated and that the merit of the merging institutions played no role. A number of subjects interviewed, from all three merging institutions, failed to comprehend how a merger between a technikon and a university can be successful, given the differences in terms of nature, culture, ethos and operations between a traditional university and a technikon.

Positive reactions expressed toward the merger have there origins in: the need to further national agendas (such as transformation in higher education, employment equity and the redress of imbalances); opportunities presented by the merger (such as access to a larger resource base, a larger variety of programs, articulation possibilities between academic and vocational streams, an expansion of research opportunities, and increased organisational effectiveness through rationalisation); and an individual preference for change. The following annotations bear testament to the abovementioned dimensions:

...when the cabinet announced that we are to merge, I had a feeling that merit was not a deciding factor, it was not considered, it was a political move

- Professor: Faculty of Education, ex-RAU

And I had reservations, and I still do, about throwing the two together into a Comprehensive Institution

- Lecturer: Faculty of Humanities, ex-RAU

Look, maybe I experienced it differently to most other people, because I am somebody that welcomes change, and, um...you know, if things continue on the same old monotonous way then something's wrong

- "Bert": Faculty of Health Sciences, ex-TWR

But the possibilities it creates, um...for a university with comprehensive tuition, this excites me. So that, you know...articulation, these articulation possibilities are better now than they were before

- "Ryno": Faculty of Natural Sciences; ex-RAU

When the first announcement was made that there was a certain national consideration that comes from the national office, in terms of the status of higher education at the time, with particular reference to the institutional landscape and also, um...the endowment variations and also the issue of quality of education offered in higher education institutions. Basically that was the rationale and for me it made every bit of sense

- "Sihle": Faculty of Humanities, ex-TWR

\section{Theme 3: Academics' Fears and Concerns Pertaining to the Merger}

Reactions to the merger were accompanied by certain concerns and fears of what the merger would imply. There was no evidence to suggest that individuals that exhibited negative reactions tabled more 
concerns than those staff members expressing positive sentiments. Many of these fears and concerns can be viewed as direct, emotionally-driven responses to a change event that staff had no knowledge of. The main concern centred around the uncertainty associated with the pending change. Factors such as job security, redeployment and relocation of facilities to other campuses and general disruption of individual comfort zones were associated with this concern. Another, albeit more emotive, concern centres around letting go of certain aspects of the merging institutions' identity, nature, ethos and culture that individuals from these institutions identify with which, it could be argued, are elements that contribute to one's comfort zone.

Prevalent particularly from ex-RAU interview subjects was the concern that UJ would be a university of lesser standing. The concern was expressed that UJ would not be a research focussed university, but a so-called "foundation university" where research activities were of secondary importance. Smaller faculties and departments of disproportionate representation from the precursor institutions felt that they would be usurped into the bigger institution, thus disregarding the efforts of small groups of dedicated academics that have toiled to position their programs, offerings and research areas. This loss of autonomy, coupled with the perceived loss of status as a research university, has leads academics to feel that the merger would lead to a drop in standards, not only in terms of academic standards, but also in terms of student calibre and research output. Interview subjects also seemed to be at odds with the concept of a Comprehensive Institution. Indeed, the government had not given any guidelines in terms of exactly what a Comprehensive Institution was supposed to be. Thus, in an effort to make sense of the concept, individuals have started to tentatively construct their own mental pictures of what a Comprehensive Institution is. The following statements are illustrative of the above sentiments:

I sensed much uncertainty, people worried about loosing their jobs, or that they will be redeployed; that they will be sent to another campus that they do not necessarily want to go to

- Senior Lecturer: Faculty of Education, ex-RAU

And because we merged with a technikon, I realised that they had made up their minds that we were not going to be a research university.

Professor: Faculty of Education, ex-RAU At one stage there was talk that we [FADA] were going to become part of a school and loose our autonomy as a faculty, and that was quite frightening.

And I'm not going to drop my standard to help those guys get through it. And those standards are going to give way, and unfortunately standards are going to drop, it not going to increase

- "Tania": Faculty of Management, ex-RAU

UJ is Vista, Wits Tech and RAU; and by imposing a new culture from the top down...you destroy the existing culture amongst staff, amongst students and in the community the campus is rooted in

- Lecturer: Faculties of Humanities, ex-Vista

There's no simple definition for it. Now, this week, in a strategic planning meeting, I said, lets accept comprehensivity as here I get...you come to the institution and eventually obtain a doctorate; You enrol, here, for a certificate and you follow this path, and eventually, after 20 or 30 years, you obtain a doctorate; let's accept that as comprehensivity

- "Andrew": Faculty of Management. Ex-RAU

\section{Theme 4: Academics' Experience of Gearing up for Merger}

The pre-merger phase implied different things for individuals from the different merging institutions. As detailed, the creation of UJ consisted of two discernable stages, the incorporation of the two Vista Campuses into RAU followed, one year later, by the eventual merging of RAU and TWR. Interview subjects from the ex-RAU and ex-Vista therefore included views on the incorporation of the Vista campuses into their reflections of the pre-merger phase, whereas ex-TWR staff - not being party to the incorporation - obviously did not reflect on the Vista incorporation. The general sentiment was that the incorporation of the Vista campuses into RAU was a relatively smooth process that caused minimal disruption to all involved. However, there was criticism launched against the process itself, stating that maintaining a "holding position" might not have been the best option. The effect of this incorporation was 
of concern to ex-Vista staff, stating that during the merger-planning phase of 2004, Vista was effectively a non-entity in the TWR/RAU deliberations.

The formal pre-merger (or merger planning) phase basically spanned 2004, and a number of interview subjects indicated that their feeling about the merger had changed during this time. Exclusively exhibiting a positive change, most subjects ascribe this change to rational self-discourse over time or exposure to merger related information. The merger-planning phase was generally perceived as a stressful period for all involved, and reflections on the merger planning revealed that the timeframe involved was a limiting factor to proper planning, leading to too many compromises in the interest of expediency. The impression also exists that RAU entered the planning phase being better prepared than their TWR counterparts. The consultative process followed during the merger-planning phase tended to expounded upon by staff on the higher hierarchical levels. Lower hierarchical levels either did not reflect upon the consultative process or reported that they were not part of the process, even stating that the consultative process was "a farce". Some individuals did feel that consultation was cosmetic to an extent, viewing the consultative process as an effort by management to at least appear to be consulting with staff. The greatest sentiment expressed, however, was that there was too much consultation taking place. This was deemed to stem from a sensitivity on the side of management to include everybody in the process and a cautious stance of not wanting to offend any party or parties in the process. Perceptions pertaining to formal communicative efforts during the merger planning phase tended to vary greatly and there was no evidence to suggest polarisation of opinion emerging from merging institutions or campuses. Although communication was perceived to be frequent, thus contributing to an awareness of the merger process, the majority of interview subjects reflected that the communicative efforts were not as effective as they could have been.

The merger-planning phase was also the first time many individuals were exposed to and started interacting with their counterparts from the other merging institutions. Interview subjects reflected that generally this initial contact seemed to be "very collegial, courteous and business-like". However, this was perceived to be a front for a condescending, antagonistic and aggressive demeanour exhibited by merging partners. Subjects specifically mentioned that ex-RAU staff seemed to view merging partners as inferior; whereas the ex-TWR was viewed as snobbish, brash and confrontational. The merger-planning phase was therefore also accompanied by the first signs of political manoeuvring at all levels from all merging partners. At lower levels, this political manoeuvring was perceived to be limited to obstinacy by parties to drive pertinent positions home. However, interview subjects perceived a lot of political infighting and jockeying for position at top management level. A lot of political manoeuvring can also be ascribed to people slipping into a "survival mode", as any situation of insecurity can cause individuals to position themselves in such a manner that they feel secure. Thus some individuals can manipulate the status quo to their own benefit; this, of course, is a very human response. The following statements further support the views as described above:

And another thing. This has not been a merger of equals. Look, for all intents and purposes, Vista was not merged. It never was an equal partner throughout

- Lecturer: Faculty of Law, ex-Vista

In the light of being confronted with it, that it must happen, your mind changes in a way that you say, we should try and do this

- "Gert": Faculty of Law, ex-RAU

I think one of the biggest problems that we had at the technikon was a limitation on the amount of people that we could optimally utilise. Um...whereas if you look at our merging partner, they planned much better for this and they had a larger pool, and they prepared people better; we had, and you would also be aware of this, we had a small pool of people and we duplicated over various areas. I personally think that at the end of the year there were too many compromises, I think there was too much that they wanted to...just to expedite the process and to say, we will enter 1 January 2005 with an Academic Structure, an Admin Structure, with this, with that.

- "Bert": Faculty of Health Sciences, ex-TWR

There's also been too much communication about the wrong things. I mean, if I open up another allusers that tells me about a vacant post in some obscure department, I think I'm going to throw a hissy-fit.

- "Angela": Faculty of Natural Sciences, ex-TWR 
Also, I think the so-called consultation was a farce. I think it was a mock-democracy

- Lecturer: Faculty of Humanities, ex-RAU

Feels that there is a tendency to want to include too many parties and people in decisions, and that this 'all inclusive' approach is stifling creativity

- Head of Department: Faculty of Management, ex-TWR (from field notes)

...I think something that continues throughout are the political games people play. Um...initially there were a lot of political agendas. This got diluted over time as people started realising that there is more than politics at stake here. The importance to save this institution and make a success of it started hitting home at middle...tactical and operational level. Then they stopped their political games. But I think politics are still rife at top management level; somewhere between the executive management and the council.

- "Andrew": Faculty of Management. Ex-RAU

We were always formally invited to provide input if we had any to give, but at the same time we were informed of 'our' intentions, implying that there was already a solid strategy in place to see the negotiations through, and input was only required as far as it supported the plans / strategies of the spokespeople

- Senior Lecturer: Faculty of Management, ex-TWR

\section{DISCUSSION}

This section firstly presents the conclusions based on the findings of the study and then presents the forthcoming managerial implications.

\section{Conclusions Resultant from the Study}

Characteristic of exploratory (qualitative) research is the rich data typically generated by the open-ended methodology employed. The themes extracted from the dataset echo this general observation. Moreover, apart from generating an array of strong hypotheses for further research of both a qualitative and quantitative nature, the results obtained in this study align substantially with several known knowledge perspectives. As this pre-merger phase (or "past" perspective) can be divided into two discernable event horizons (one which is emotively driven - reaction to the merger - and the other very much dependent on rational discourse - merger planning), the main findings as they pertain to academics' experience of the pre-merger phase, and their primary implications, are briefly considered from these perspectives.

\section{Individuals' initial reaction to merger}

Immediately after announcement of a proposed merger, individuals tend to act overwhelmingly from an emotive frame of reference, which tends to support Van Tonder's (2004b:181) argument that cognitive processes may be less prevalent during reaction to a change event, and thus it is more of an immediate response. These emotive reactions are fuelled by five variables. Findings indicate that these variables are not interconnected, which would contribute to the emotive nature of reactions. These variables are:

- Reasons given for merger: As the merger was clearly ideologically and politically motivated, disagreement with the reasons provided by the government abounded and gave rise to negative reactions amongst academic staff. Literature also presents evidence of staff being at odds with the reasons given for a merger. Erikson and Sundgren (2004:10) found this same phenomenon in their study of the merger between the pharmaceutical companies Astra and Zeneca.

- Fears: The overall lack of information directly following the announcement to merge gives rise to certain unfounded fears, a reality the merging institutions were all too aware of (Anon, 2005a; Anon, 2005b and Van Der Merwe, 2005), and supported by literature (Fulop et al., 2005:128; Papadakis, 2005:241; Robbins, 2001:546; Shin, 2003:12 and Van Tonder, 2004b:177).

- Personal outlook: Concerned with the individual's predisposition to change as well as the degree of change readiness exhibited by the individual, there were individuals that cited their personal preference 
for - or fear of - change, which would suggest that a certain predisposition to change would be present in all individuals (Van Tonder, 2004b:163). Change readiness refers to the degree to which staff are willing to accept change (Darling, 1993, in Van Tonder, 2004b:163). It could be argued that a positive predisposition to change is helpful in making individuals change-ready, but it does not seem to be a pre-requisite, as is evident from the study. A product of both personal characteristics and exposure to change, the personal outlook of an individual shows no dependency on the other variables, which shape a person's reaction to a proposed merger.

- Opportunities presented by the merger: People both positively and negatively disposed to the merger tended to see opportunities in the UJ merger. Although there is no evidence forthcoming from literature to support the effect of opportunities presented by a merger on individuals' attitude toward the merger, there is evidence that mergers are often seen as providing opportunities for shared learning; collaboration; growth and healing, implying a positive connotation toward a merger (Leroy \& Ramanantsoa, 1997 and Van Tonder, 2004b:163).

- Institutional Predisposition: There is evidence to suggest that the organisation forms an integral part of people's "social identity" and, in a merger situation, the visibility of membership becomes high and hence the social identity based on the pre-merger organisation becomes salient (Anstey, 2006:360; Hogg \& Terry, 2000 and Shin, 2003:15-16). The concept of organisational predisposition, however, links the "social identity" to actual attitude toward the pending merger; as identified - although not so termed - by Haunschild, Moreland and Murrell (1994) and supported by Shin (2003:54). As is evident from the findings, the way individuals perceived the institution they hailed from has a strong influence on individuals' level of job satisfaction. What was most evident from the findings, is that a negative predisposition overrode disagreement with reasons to merge, fears associated with the merger and, to a lesser extent, even personal outlook.

\section{The merger-planning stage}

The outlook of individual staff members during the merger-planning stage seemed to differ considerably from their initial reaction to the announcement of the merger. The planning stage is typified by heightened rationality; six interrelated variables have been identified that shape individuals' outlook and attitudes toward the merger during this stage, these are:

- The merger-planning process: Central to this stage of the merger is the core activity of this stage, planning for the merger at hand. As time progressed, staff gradually came into contact with merger related information. First and foremost in this regard was formal communicative efforts embarked upon by the respective merging institutions (RAU, Vista and TWR). Although formal communication was deemed not to be as effective as people - academics and management alike (Anon, 2005b and Van Der Mewe, 2005) - would have liked, it still served a purpose. Supplementing the formal communication was information forthcoming from the media, peers, trade-unions, merging partners and personal contacts privy to information of limited distribution. All these sources of information lead to more rational self-debate and discourse. The consultative approach followed by the merging partners called for staff at all levels to become involved in the process. Although there is a feeling that this consultative approach was taken a bit too far at times and thus a major contributing factor in merger planning events being perceived as slow paced; the value of this all inclusive, consultative approach is not to be undermined in that it heightened awareness of merger related issues, thus contributing to more rational discourse and opinion on the subject.

- Personal paradigms: The passage of time, coupled with a more rational demeanor, and exposure to the beginnings of the merger process, results in an attitudinal change when compared to the initial reaction to the announcement of the merger. It is safe to conclude that these paradigm shifts affected the quality of merger planning efforts positively, as individuals who underwent such shifts were more focused on the interests of the merged institution. The need for this type of attitudinal shift was, for example, something that was lacking in the merger between Astra and Zeneca, a shortcoming identified by managers involved in that merger (Eriksson \& Sundgren, 2004:10). 
- Planning timeframe: Literature would suggest that the merger planning stage has to be afforded the luxury of time to ensure successful roll-out (Eriksson, 2004:5). Unfortunately, the University of Johannesburg was not afforded this luxury, a source of much aggravation for staff as the issues not resolved in the planning stage inadvertently filtered through to the merger implementation phase.

- Initial contact: The planning stage was typified by formal contact between future colleagues for the first time. As the findings indicate, future colleagues did not necessarily welcome each other with open arms. Not reason enough to negatively dispose staff, such experiences can have a negative impact on planning efforts and milieu in general as it creates an opportunity for political undertones. Evidence of this type of tumultuous interaction can be found in European mergers, such as the merger between Volvo Aero and Norwegian Jet Engine (Jonsson et al., 2004:9). However, Vermeulen (2005:49) points out that this type of interaction is necessary and should be viewed as part of a larger effort to reexamine old methods and routines.

- Politics: Again, not reason enough to sway opinion to negativity in terms of outlook toward the merger, it could negatively impact the overall milieu of the merger. This is a relatively common occurrence in large-scale change (Eriksson, 2004:4-5 and Robbins, 2001:548), as people want to cling to known conventions; be these conventions daily routines and operating procedures, access to information, control over resources or power. The commonness of this type of behaviour does not detract from the fact that perpetuating any old status quo is a debilitating factor in any merger (Anstey, 2006:346).

- Concerns: Whereas the reaction stage was typified by emotive - and often irrational - fears, the rational nature of the planning stage gave rise to concerns based on individuals' experiences. These concerns were based on the process as it was unfolding. In some instances, these concerns supported the initial irrational fears people possessed but, in general, these concerns were extrapolated to a future implication on the individual and institution. However, be they irrational fears or grounded concerns, these anxieties are part and parcel of the process, at all stages (Fulop et al., 2005:128).

\section{MANAGERIAL IMPLICATIONS}

The study revealed that the principle of the merger is a concept that staff are still grappling to come to terms with. Although there is acceptance of the merger, one gets the feeling it is more of "giving in" to the idea rather than firm belief in the idea. Thus, although the sentiment seems to be positive on the surface, scrutiny of the data reveals that there are still many reservations, and very few subjects are overtly of the opinion that they believe in the University of Johannesburg. This is an area that necessitates the intervention of strong strategic leadership. Only through intensive and unambiguous guidance from a firm and decisive leadership corps, can true buy-in to the idea of the University of Johannesburg be achieved. Although this process will be time-consuming, arduous and frustrating; it will be cardinal for positioning UJ as a flagship institution in the South African HEI landscape.

Also evident from the findings was the way individuals perceived the institution they hailed from and the effect this had on the individuals' level of job satisfaction. The more favourable this institutional predisposition, the less favourable individuals tended to be to the announcement of the merger. Although it can be argued that a person with a very positive predisposition will be less change-ready, be more fearful of a merger, and will be at loggerheads with the reasons provided for merger, this correlation was not forthcoming from the interviews and can thus not be argued with any substance in this case. What was evident from the findings is that a negative predisposition overrode disagreement with reasons to merge, fears associated with the merger and, to a lesser extent, personal outlook to change. The mere prospect of "working for a new employer", or a shake-up (and possible rectification of the inefficiencies) of the current status quo was reason enough for people to be supportive of the merger. As organisational predisposition is a product of entrenched attitudes, it is not something that disappears when a new institution such as $U \mathrm{~J}$ is born out of a merger. The challenge that the management of the university is faced with is to harness this organisational predisposition as point of departure to inculcate an organisational disposition amongst staff toward the University of Johannesburg. 
Although the consultative process of merger planning was both positively and negatively perceived by academics, negative perceptions hereof can do more harm than positive perceptions can add value. Seen as an essential element in creating buy-in into the UJ-idea and for inculcating an organisational disposition toward UJ, all-inclusive and genuine consultation on the correct issues is sorely needed at UJ. This would necessitate innovative ways of consulting with all stakeholders. Although formal communications are deemed to be both successful and unsuccessful by academics, one has to admit that the negative sentiment uttered is cause to improve these efforts. The evidence suggests that there is a definite need for more focused, operational level communication as well as more intensive communication.

\section{CONCLUSION}

This paper has attempted to shed light on individual experiences of a merger, more specifically the experiences of academic staff during the pre-merger phase. This study indicates how individuals reacted to the merger of RAU and TWR into the University of Johannesburg and how these reactions set the tone for the eventual merger implementation. To date, the extant literature appears to have directed scant attention to individual experiences of a merger. Knowledge of how individuals experience the pre-merger phase of a change event such as a merger will enable business leaders to tailor change management interventions to negate the effect of these often overlooked human aspects of large-scale change and facilitate more effective execution of the merger.

\section{REFERENCES}

Anon, 2001a. Conference board study reveals who really benefits from mergers. In: Mergerwatch. Edition 3 - 24 September 2001:3.

Anon, 2005a. (Past member of UJ Interim Executive Management). Personal interview conducted on 18 November 2005 in Johannesburg.

Anon, 2005b. (Past Interim Executive Dean at UJ). Personal interview conducted on 19 October 2005 in Johannesburg.

Anstey M. 2006. Managing change, negotiating conflict. Cape Town: Juta.

Applebaum SH, Gandell J, Shapiro BT, Belisle P \& Hoeven E. 2000b. Anatomy of a merger: behavior of organizational factors and processes throughout the pre- during- post-stages (part 2). Management Decision, 38(10):674-684.

Applebaum SH, Henson D \& Knee K. 1999. Downsizing failures: An examination of convergence /reorientation and antecedents - processes - outcomes. Management Decision, 37(6):473-490.

Armenakis AA \& Harris SG. 2002. Creating a change message to create transformational readiness. Journal of Organizational Change Management, 15(2):169-183.

Babbie E \& Mouton J. 2004. The practice of social research. Cape Town: Oxford University Press.

Bews N. 2001. Maintaining trust during organisational change. Management Today, 17(2):36-39.

Cairncross F. 2003. The company of the future. Meeting the management challenges of the communication revolution. London: Profile Books.

CIPD (Chartered Institute of Personnel and Development). 2000. Survey report: People implications of mergers and acquisitions, joint ventures and divestments. September 2000. London: CIPD.

Collins JC \& Porras JI. 2000. Built to last: Successful habits of visionary companies. London: Random House: London. 
Corbin J \& Straus A. 1990. Grounded Theory research: Procedures, canons, and evaluative criteria. Qualitative Sociology, 13(1):3-21.

Denzin NK \& Lincoln YS. 2005. Introduction: The discipline and practice of qualitative research. In NK Denzin \& YS Lincoln (Eds.). The Sage handbook of qualitative research. 3rd ed. Thousand Oaks: Sage.

Du Plessis AJ. 2004. Conflict during the changing process: HR's role in 2002 and 2010. Paper presented at the $7^{\text {th }}$ IFSAM (International Federation of Scholarly Associations of Management) World Conference $5-7$ July 2004 Goteburg, Sweden and published on Conference Proceedings CD-ROM.

Ensor L. 2003. Commission challenges job losses report: Mergers have resulted in job creation. In: Business Day, 30 September 2003, 4.

Eriksson PE. 2004. Barriers to change: Implementation of partnering in the Swedish construction industry. Paper presented at the $7^{\text {th }}$ IFSAM (International Federation of Scholarly Associations of Management) World Conference $5-7$ July 2004 Goteburg, Sweden and published on Conference Proceedings CD-ROM.

Eriksson M \& Sundgren M. 2004. Managing change: Strategy of serendipity? Reflections from the merger of Astra and Zeneca. Paper presented at the $7^{\text {th }}$ IFSAM (International Federation of Scholarly Associations of Management) World Conference 5 - 7 July 2004 Goteburg, Sweden and published on Conference Proceedings CD-ROM.

Fulmer RM \& Gilkey R. 1988. Blending corporate families: Management and organizational development in a postmerger environment. Academy of Management Executive, 2:275-283.

Fulop N, Protopsaltis G, King A, Allen P, Hutchings A \& Normand, C. 2005. Changing organisations: a study of the context and processes of mergers of health care providers in England. Social science and medicine, 60(2005):119-130.

Garratt, B. 2000. The learning organisation. Developing democracy at work. London: Harper-Collins.

Goldman GA. 2005. The management of change at the University of Johannesburg. Paper presented at the $16^{\text {th }}$ Southern Africa Institute for Management Scientists Conference, 26-28 November 2005 in Bloemfontein, South Africa and published on Conference Proceedings CD-Rom.

Goldman GA \& Coetzee J. 2004. Change readiness for the University of Johannesburg. Paper presented at the $3^{\text {rd }}$ TUT / Polytechnic Namibia International conference, 3-4 November 2004 in Pretoria, South Africa and published on Conference Proceedings CD-Rom.

Hattingh B. 2004. Ups and downs of mergers, acquisitions. Business Day, July 19, 1st edition.

Haunschld PR, Moreland RL \& Murrell AJ. 1994. Sources of resistance to mergers between groups. Journal of applied psychology, 24:1150-1178.

Henning E, van Rensburg W \& Smit B. 2004. Finding your way in qualitative research. Cape Town: Van Schaik.

Hogg MA \& Terry D. 2000. Social identity and social comparison. In: Suls J \& Wheeler L.: Handbook of social comparison: Theory and research. New York: Kluwer Academic.

Jonsson S, Rovio-Johansson A \& Kokk G. 2004. Arguing your case on principles of management in a merger context. Paper presented at the $7^{\text {th }}$ IFSAM (International Federation of Scholarly Associations of Management) World Conference 5 - 7 July 2004 Goteburg, Sweden and published on Conference Proceedings CD-ROM. 
Kotter JP. 2002. The heart of change. Real life stories of how people change their organisations. Boston: Harvard Business School Publishing.

Laetoli. 2005. Proposal on creating a change enablement governance structure. Unreferenced document of limited distribution.

Leroy F \& Ramanantsoa B. 1997. The cognitive and behavioural dimensions of organisational learning in a merger: An empirical study. Journal of management studies, 34(6):871-894.

Lessing N \& Maritz G. 2001. Juxtapositions in management: Critical issues to be resolved. Management Today, 17(1):10-14.

Lew-Kiedrowski V. 2001. Change masters to see companies through modern challenges. Management Today, 17(2):22-23.

Lundback M \& Horte SA. 2005. Decision making in conditions of constant change - a case within the automotive industry. Management Decision, 43(2):220-235.

Mokadi CC. 2002. Address at an Informational Dinner to discuss the Technikon Witwatersrand's perspectives on the Merger Proposals of the Ministry of Education. Transcript of dinner address held on 31 July 2002. Undistributed document.

Morrell KM, Loan-Clark J \& Wilkinson AJ. 2004. Organisational change and turnover. Personnel Review, 33(2):161-173.

Mouton J. 1996. Understanding social research. Pretoria: Van Schaik Publishers.

Nel PS, Marx AE \& Burchell RN. 2004. Business management challenges regarding the future of work and change - Human resources managers' perspectives for the following decade. Paper presented at the $7^{\text {th }}$ IFSAM (International Federation of Scholarly Associations of Management) World Conference 5 7 July 2004 Goteburg, Sweden and published on Conference Proceedings CD-ROM.

Neuman WL. 2003. Social Research Methods: Qualitative and quantitative approaches. Boston: Allyn \& Bacon.

Panchal S \& Cartwright S. 2001. Group differences post-merger stress. Journal of Managerial Psychology, 16(6):424-433.

Papadakis VM. 2005. The role of broader context and the communication program in merger and acquisition implementation success. Management Decision, 43(5):236-255.

Peterhoff D. 2004. Designing HR due diligence in the context of mergers and acquisitions. Paper presented at the $7^{\text {th }}$ IFSAM (International Federation of Scholarly Associations of Management) World Conference $5-7$ July 2004 Goteburg, Sweden and published on Conference Proceedings CD-ROM.

Pettigrew A. 1990. Longitudinal research and change: Theory and practice. Organization Science, 1:267-292.

Robbins SP. 2001. Organisational behaviour. Upper Saddle River: Prentice Hall.

Schafer L. 2004. Is the honeymoon over? Looking at the marriage of SAS and Marketmax. SAScom. $4^{\text {th }}$ quarter 2004:48-49.

Shin SJ. 2003. Facilitating inclusive identity: HR practices, perceived fairness and intergroup cognitions in corporate mergers. Unpublished PhD thesis, Texas A\&M University. 
Technikon Witwatersrand. 2002a. A new institutional landscape for higher education in South Africa. Official Bulletin 05/2002 [Online] Available from: http://twr.ac.za/intranet/1/3/5/bulletin052002.doc [Accessed: 23/06/2004].

Technikon Witwatersrand. 2002b. Update five: A new institutional landscape for higher education in South Africa. Official Bulletin 09/2002 [Online] Available from: http://twr.ac.za/intranet/1/3/5/bulletin092002.doc [Accessed: 23/06/2004].

Technikon Witwatersrand. 2003a. Important matters arising from 2002. Official Bulletin 01/03. [Online] Available from: http://twr.ac.za/intranet/1/3/5/bulletin\%2001\%20of\%2003.doc [Accessed: 24/06/2004].

University of Johannesburg. 2005a. Strategy formulation process: Progress Report no.1. 30 June 2005. Unpublished document of limited distribution.

University of Johannesburg. 2005b. Successful Institutional change. E-Merge. Issue 13: 03/06/2005.

Van Der Merwe D. 2005. (Past Deputy Vice Chancellor: Academic of RAU and UJ and current Pro-Vice Chancellor of UJ). Personal interview conducted on 27 October 2005 in Johannesburg.

Van Tonder CL. 2004a. "Organisational transformation": Wavering on the edge of ambiguity. South African Journal of Industrial Psychology, 30(3):53-64.

Van Tonder CL. 2004b. Organisational change: Theory and practice. Pretoria: Van Schaik.

Van Tonder CL. 2005. The unacknowledged contribution of organisational change practice to organisational and employee wellness. Paper delivered at the International Conference on the Changing World of Work, 8-9 March, Vanderbijl Park, South Africa.

Vermeulen F. 2005. How acquisitions can revitalise companies. MIT Sloan Management Review, 46(4):44-53.

Wenburg J. 2001. Thriving in permanent whitewater. Management Today, 17(7): 6-7. 